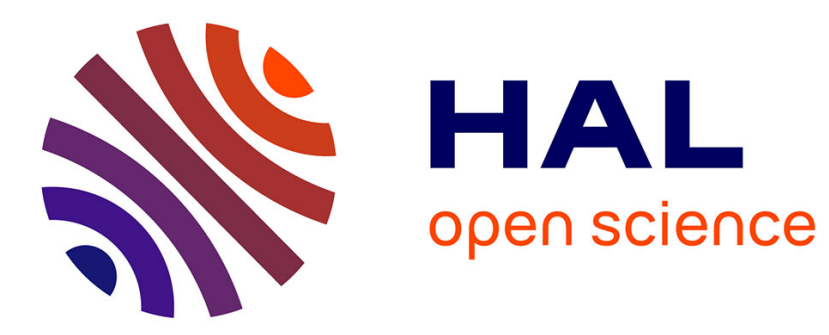

\title{
Structure of cation interstitial defects in nonstoichiometric rutile
}

\author{
L.A. Bursill, M.G. Blanchin
}

\section{To cite this version:}

L.A. Bursill, M.G. Blanchin. Structure of cation interstitial defects in nonstoichiometric rutile. Journal de Physique Lettres, 1983, 44 (4), pp.165-170. 10.1051/jphyslet:01983004404016500 . jpa-00232175

\section{HAL Id: jpa-00232175 https://hal.science/jpa-00232175}

Submitted on 1 Jan 1983

HAL is a multi-disciplinary open access archive for the deposit and dissemination of scientific research documents, whether they are published or not. The documents may come from teaching and research institutions in France or abroad, or from public or private research centers.
L'archive ouverte pluridisciplinaire HAL, est destinée au dépôt et à la diffusion de documents scientifiques de niveau recherche, publiés ou non, émanant des établissements d'enseignement et de recherche français ou étrangers, des laboratoires publics ou privés. 
Classification

Physics Abstracts

$61.70 \mathrm{~B}-61.70 \mathrm{P}-61.70 \mathrm{Y}$

\title{
Structure of cation interstitial defects in nonstoichiometric rutile
}

\author{
L. A. Bursill (*) and M. G. Blanchin \\ Département de Physique des Matériaux $\left({ }^{* *}\right)$, Université Claude Bernard, \\ Lyon I, 43, Boulevard du 11 Novembre 1918, 69622 Villeurbanne Cedex, France
}

(Reçu le 16 août 1982, révisé le 14 décembre, accepté le 3 janvier 1983)

\begin{abstract}
Résumé. - On présente ici de nouveaux modèles de défauts interstitiels pour accommoder la nonstoechiométrie du rutile peu réduit $\mathrm{TiO}_{2-x}$. Ces défauts consistent en des arrangements linéaires, le long de directions [100] ou [010], de paires de cations trivalents situés au centre d'octaèdres d'oxygène ayant une face en commun. On décrit ensuite les mécanismes de diffusion permettant l'aggrégation de tels défauts pour donner naissance à des paires de plans de " cisaillement cristallographique ", ainsi que cela a été récemment observé en microscopie électronique à haute résolution dans des cristaux $\mathrm{TiO}_{2-x}$ refroidis relativement lentement depuis la température de réduction de $1050^{\circ} \mathrm{C}$. Des considérations relatives à l'énergie électrostatique expliquent pourquoi ces défauts ont une énergie de formation et de migration beaucoup plus basse que les défauts « ponctuels » traditionnels.
\end{abstract}

\begin{abstract}
New cation interstitial defect models are derived for substoichiometric rutile $\mathrm{TiO}_{2-x}$. These consist of linear arrangements, along [100] or [010], containing two face-shared octahedral pairs of trivalent cations. Diffusion mechanisms are described whereby these may readily aggregate to form pairs of crystallographic shear planes, as observed recently by high-resolution electron microscopy, when $\mathrm{TiO}_{2-x}$ specimens are cooled relatively slowly from $1050^{\circ} \mathrm{C}$. Electrostatic arguments explain why these defects have very much lower formation and migration energies than the traditional «point defect » interstitial model.
\end{abstract}

1. Introduction. - Considerable uncertainty remains concerning the nature of the structural defects responsible for the phase $\mathrm{TiO}_{2-x}$ (see e.g. Akse and Whitehurst [1], for a recent literature survey). Most interpretations of physical property and resonance technique measurements have been based upon models for point defect equilibria (see e.g. Kofstad [2]).

Bursill and Hyde [3] questioned whether "classical " point defects occurred in reduced rutile since $\mathrm{TiO}_{1.9986}$, well annealed at $1000^{\circ} \mathrm{C}$ and then slowly cooled, contained lamellae of crystallographic shear planes (CSP) coexisting with a maze of intersecting $\left.\{1 \overline{3} 2\}<0 \frac{1}{2} \frac{1}{2}\right\rangle$ CSP. The latter was identified as the nonstoichiometric phase $\mathrm{TiO}_{2-x}$. However, the interpretation of electrical conductivity measurements by Baumard, Panis and Anthony [4] and of quenching experiments followed by electron diffraction contrast studies (Blanchin, Faisant, Picard, Ezzo and Fontaine [5]) suggested that for $\mathrm{TiO}_{1.9920-2.0000}$ the equilibrium phase existing at $1050{ }^{\circ} \mathrm{C}$

(*) Permanent Address : School of Physics, University of Melbourne, Parkville, 3052, Victoria, Australia.

$(* *)$ Associé au C.N.R.S. 
contains no CSP. High-resolution electron microscope (HREM) studies of a number of $\mathrm{TiO}_{2-x}$ preparations $(0<x<0.0035)$, reduced at $1323 \mathrm{~K}$ and given a variety of thermomechanical histories, showed new phenomena (Blanchin, Bursill, Hutchison and Gai [6] ; Bursill, Blanchin and Smith [7] ; Smith, Blanchin and Bursill [8]). Thus CSP were not present, even en miniature, in non-deformed crystals quenched from $1323 \mathrm{~K}$, but did appear, frequently as very closelyspaced pairs, in more slowly cooled or reduced and deformed specimens. HREM revealed both lateral and longitudinal disorder within the structure of the CSP, the details of which were strongly dependent upon cooling histories. Many of the HREM images showed "spot " contrasts which suggest the presence of small ( $<20 \AA$ diameter) defects. Recent electrical conductivity studies over a wider range of temperatures $(T)$, and for relatively high partial pressures of oxygen $\left(\mathrm{O}_{2}\right)$ (Marucco, Gautron and Lemasson [9], Gautron, Marucco and Lemasson [10]) suggest that there are three domains within the $\mathrm{TiO}_{2-x}$ phase, where the predominant defects are assumed to be :

I interstitial $\mathrm{Ti}_{i}^{4}$, prevailing for $T>900^{\circ} \mathrm{C}$ and for relatively low partial pressures of oxygen;

II doubly ionized oxygen vacancies $\mathrm{V}_{\ddot{\mathrm{o}}}$, prevailing at lower temperatures and for increasing $p \mathrm{O}_{2}$, and

III another oxygen vacancy defect, initially interpreted as a single ionized oxygen $\mathrm{V}_{\dot{\mathrm{o}}}$ (Marucco et al. [9]) but later attributed to oxygen vacancies associated with charge compensation of aliovalent $\mathrm{Me}^{3+}$ impurities (Gautron et al. [10]) prevailing for $x<0.00016$, independent of $p \mathrm{O}_{2}$ or $T$.

In this letter we present new models for cation interstitial defects which were derived in an attempt to extend the structural principles of CS (previously identified to apply throughout most of the stoichiometry range $\mathrm{TiO}_{1.5000}-\mathrm{TiO}_{2.0000}$ ) to account for the structure of interstitial defects in non-stoichiometric rutile. New structure models for anion vacancy and impurity defects will be presented elsewhere (Bursill and Blanchin, in preparation).

2. Derivation of interstitial structure. -2.1 TRADITIONAL CATION INTERSTITIAL STRUCTURE. Figure 1a depicts the [010] bounded projection $\left(-\frac{1}{4}<y<\frac{1}{4}\right)$ of the rutile structure, using the familiar octahedral representation. The $\frac{1}{4}<y<\frac{3}{4}$ bounded projection is symmetrically equivalent. (In earlier work it was convenient to take the corresponding [010] section, see Bursill

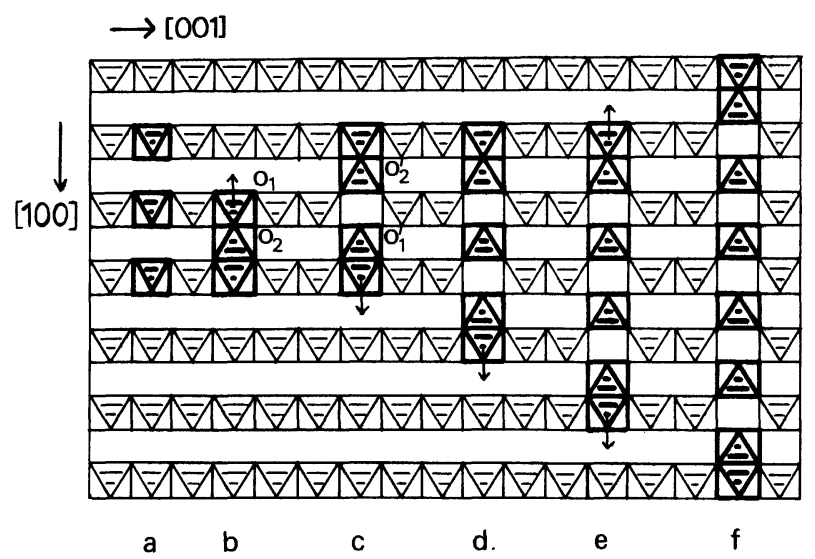

Fig. 1. - Bounded projection (along [100], for $-\frac{1}{4} \leqslant x \leqslant \frac{1}{4}$ ) of the structure of rutile, containing : a) no defect; b) traditional interstitial defect, i.e. additional $\mathrm{Ti}^{3+}$ cations; c) two pairs of octahedrally-coordinated $\mathrm{Ti}^{3+}$ cations sharing faces; d), e) and f) show linear extensions of c) to produce more widely-separated pairs of face-shared octahedra. 
and Hyde [3], the use of [010] in the present work proved surprisingly instructive.) Rutile is tetragonal with cell parameters $a=4.5937 \AA$, space group $\mathrm{P}_{4} / \mathrm{mnm}$ with $\mathrm{Ti}$ at $000 ; \frac{1}{2} \frac{1}{2} \frac{1}{2}$ and $\mathrm{O}$ at $u u 0$; $\overline{u u} 0 ; \frac{1}{2}-u, \frac{1}{2}+u, \frac{1}{2}$ and $\frac{1}{2}+u, \frac{1}{2}-u, \frac{1}{2}$ with $u=0.3053$. Octahedrally coordinated interstitial sites may be found at $\frac{1}{2} 00 ; \frac{1}{2} 0 \frac{1}{2} ; 0 \frac{1}{2} 0 ; 0 \frac{1}{2} \frac{1}{2}$ (see Hurlen [11]). Figure $1 \mathrm{~b}$ depicts the classical model for the interstitial in rutile, whereby a $\mathrm{Ti}^{3+}$ cation is inserted at $\left(\frac{1}{2} 00\right)$. Note the formation of a string of three face-shared octahedrally coordinated cation sites, separated by $2.3 \AA$. Analysis of the electrostatic valencies (esv ; see Megaw [12], for a discussion of this concept) of the oxygen ions (labelled $\mathrm{O}_{1}$ and $\mathrm{O}_{2}$ in Fig. 1b) associated with this model gives -2.00 for $\mathrm{O}_{1}$ and -2.5 for $\mathrm{O}_{2}$. The latter implies a large electrostatic energy for such a defect. Bursill and Hyde [3] showed that the CSP observed by electron microscopy and diffraction techniques throughout most of the stoichiometry range $\mathrm{TiO}_{1.5000-2.0000}$ all contain, as a common structural principle, pairs of face-shared octahedra linked by edge- and corner-sharing in such a way that they may be regarded as coherent intergrowths of elements of the corundum-like structure of e.g. $\mathrm{Ti}_{2} \mathrm{O}_{3}$, with the rutile matrix. Our HREM observation that pairs of CSP occurred frequently in specimens relatively slowly-cooled across the $\mathrm{TiO}_{2-x}$ phase boundary suggest that the interstitial defects may consist of two pairs of face-shared octahedra and that these then aggregate in order to produce CSP. Thus figure $2 \mathrm{a}$ shows the octahedral arrangement in a [010] bounded projection through a pair of (121) CSP. Note that cations in face-shared octahedral sites must have (formally at least) charge +3 if the correct stoichiometry $\left(\mathrm{Ti}_{2}^{3+}, \mathrm{Ti}_{n-2}^{4+}\right) \mathrm{O}_{2 n-1}$ is to be obtained for the CSP.

2.2 Alternative CATION INTERSTitial DEFECT STRUCTURE. - Figure lc shows that two pairs of face-shared octahedra may be readily obtained from figure $1 \mathrm{~b}$ by shifting one of the cations (arrowed) by vector $\left[\frac{1}{2} 00\right]$. Such a jump is formally equivalent to a cation Frenkel defect. However, this geometrical relationship is only superficial. In order to obtain a pair of CSP by aggregation of the defects shown in figure $1 \mathrm{c}$, we require a $\mathrm{Ti}^{3+}$ cation in each of the face-shared sites. We therefore take as our basic interstitial defect figure $1 \mathrm{c}$ with four $\mathrm{Ti}^{3+}$ cations. Two of these occupy octahedral interstices and two substitute for $\mathrm{Ti}^{4+}$ cations in normal cation sites. In addition

(253)

(132)

(143)

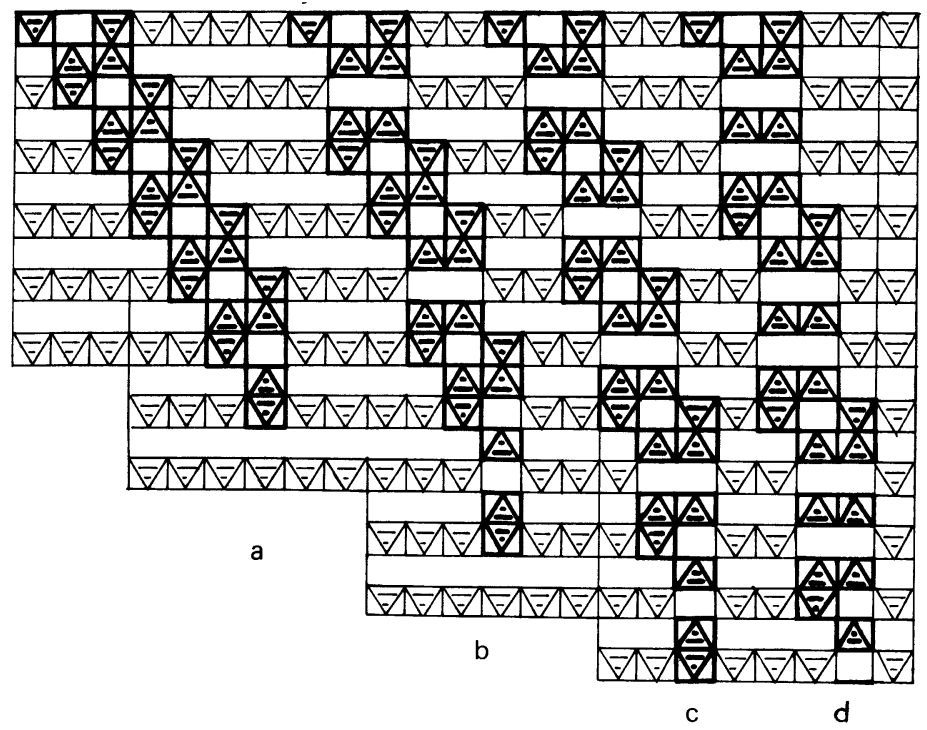

Fig. 2. - Bounded projection (along [100], for $-\frac{1}{4} \leqslant x \leqslant \frac{1}{4}$ ) of the rutile structure containing : a) a pair of (121) crystallographic shear planes (CSP); b) a pair of (253) CSP; c) a pair of (132) CSP and d) a pair of (143) CSP. 
one cation site, formerly occupied by $\mathrm{Ti}^{4+}$, is now empty. Altogether we have replaced three normal $\mathrm{Ti}^{4+}$ cations by four $\mathrm{Ti}^{3+}$ cations, giving no net change in positive change in the lattice, compared to the extra +3 charges in the classical model.

2.3 ENERGETIC CONSIDERATIONS. - This new defect model must have, at least in principle, very much lower electrostatic contributions, at both short and long-range, to both its formation and migration energies. Analysis of the electrostatic valencies of the oxygen sites show two crystallographically distinct sites (labelled $\mathrm{O}_{1}^{\prime}$ and $\mathrm{O}_{2}^{\prime}$ in Fig. 1c), with $12 \mathrm{O}_{1}^{\prime}$ having esv $=-1.833$ and $6 \mathrm{O}_{2}^{\prime}$ having esv $=-2.333$. The average esv is thus -2.0 , and we expect that ion relaxations and associated polarization of the oxygen ions (rutile has a high dielectric constant) will allow the esv of all of the oxygen ions to approach close to - 2.0. Simplistic electrostatic energy calculations, so far neglecting ion relaxations and polarization effects, using a difference-sum technique, showed that the new model is lower in electrostatic energy by $\sim 100 \mathrm{eV}$, despite the fact that it contains four $\mathrm{Ti}^{3+}$ cations compared to one for the classical model (Bursill and Shen, in preparation). More extensive calculations are in progress but it is already very clear that the new model is an extremely efficient way, both energetically and chemically to incorporate $\mathrm{Ti}^{3+}$ cations into rutile.

3. Further consideration and discussion. - 3.1 MoBILITY AND AGGREGATION OF INTERSTITIAL DEFECTS. - A pair of (121) CSP may be readily formed (Fig. 2a) by ordered aggregation of the defects shown in figure $1 \mathrm{c}$, provided that the defects are reasonably mobile. Assuming a homogeneous distribution of such defects leads to the conclusion that CSP can form in the bulk of a reduced crystal and thus are not constrained to grow from the surface. Since the displacement vector across a pair of CSP is $\mathbf{R}=0$ [Modulo 1] this may occur without necessarily creating a partial dislocation loop (of course, if dislocations already exist, as in deformed specimens, the defects may accrete to it and produce dissociation; we return to elaborate the various possibilities in another paper). Figures $3 a, b, c$ indicate sequences of cooperative atomic diffusive jumps required for mobility parallel to [001], [100] and [0 $\left.\frac{1}{2} \frac{1}{2}\right]$ respectively. Note that we assume such defects are created at the crystal surfaces, following loss of oxygen to the gas phase on reduction of rutile. These jumps can always be carried out in such a way that triple-face-sharing of octahedra is avoided. Note that essentially Frenkel defects are involved but in addition we assume an accompanying electronic conductivity according to $\mathrm{Ti}^{3+} \rightarrow \mathrm{Ti}^{4+}+\mathrm{e}^{-}$. $\mathrm{This}^{4}$ last
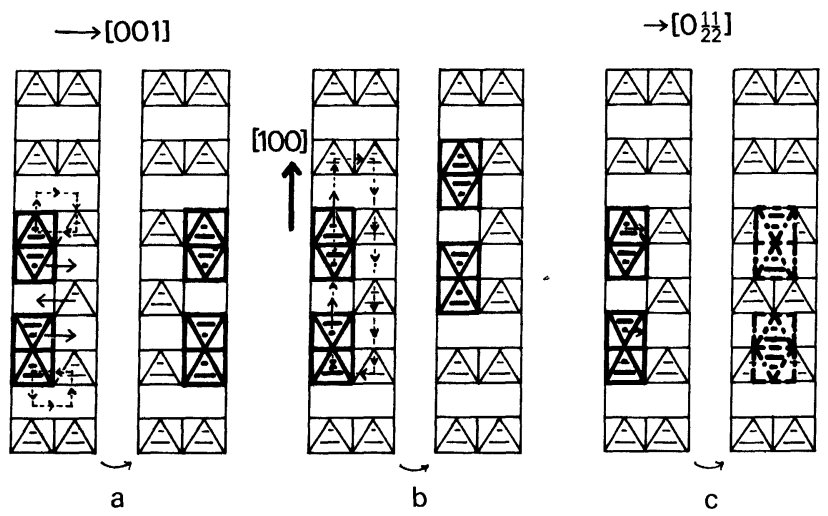

Fig. 3. - Arrows indicate suggested diffusion mechanisms for movement of $\mathrm{Ti}^{3+}$ interstitial defects parallel to a) $[001]$; b) $[010]$ and c) $\left[\frac{1}{2} 0 \frac{1}{2}\right]$. Dotted arrows indicate more complex concerted atom movements required for bulk diffusion of $\mathrm{M}^{3+}\left(\right.$ e.g. $\mathrm{Cr}^{3+}$ or $\left.\mathrm{Fe}^{3+}\right)$ interstitial defects. 
process has a low activation energy ( $\sim 0.40 \mathrm{eV}$, see Marucco et al: [9]). Similar diffusive hops allow CSP splitting, subsequent to their formation, to produce arbitrary separations (see Bursill et al. [13]).

3.2 LINEARLY EXTENDED INTERSTITIAL DEFECTS. - Our HREM observations showed that the local orientation of the CSP pairs observed in relatively slowly-cooled specimens fall between (121) and (143) with mean orientation (132). Figures $2 \mathrm{~b}-\mathrm{d}$ show the corresponding bounded projections through pairs of (253), (132) and (143) CSP respectively. This figure immediately suggests a further development of the cation interstitial model, depicted in figures $1 \mathrm{~d}, \mathrm{e}, \mathrm{f}$. Here successive $\left[\frac{1}{2} 00\right]$ atomic jumps lead to further separation of the face-shared pairs, producing linear defects having extent starting at $9.2 \AA$ and increasing to $13.8 \AA, 18.4 \AA$ or $27.2 \AA$ respectively. Orderly aggregation of such defects leads naturally to pairs of higher index CSP. Furthermore, imperfect ordering of any one type, or of a mixture of different types leads naturally to lateral and longitudinal disorder within the CSP structure, as observed by HREM. It should be noted that the linear strings of displaced octahedra connecting the face-shared pairs in these linear defects occur as elements of the (011) antiphase boundary, or microtwin lamellar structures, often observed in rutile (see Blanchin et al. [6] ; Bursill and Hyde [3]). The esv of the corresponding oxygens are -2.0 .

3.3 INTERSTITIAL DEFECTS IN DOPED SPECIMENS. - We note that CSP defects also occur in rutiles doped with $\mathrm{Fe}^{3+}$ or $\mathrm{Cr}^{3+}$. The same interstitial defects models could apply here, with $\mathrm{Ti}^{3+}$ substituted by $\mathrm{Me}^{3+}$, although as yet HREM has not been carried out to determine whether the CSP precipitate as pairs. (In such cases long-range diffusion mechanisms (dotted in Fig. 3), are required.) Thus the kinetic behaviour of doped specimens is expected to differ from that of the reduced binary system $\mathrm{TiO}_{2-x}$.

3.4 LoCALIZATION OF ELECTRONS. - It has been convenient so far to assume that $\mathrm{Ti}^{3+}$ ions are (formally) attached to the face-shared octahedral sites. In fact electrical conductivity measurements suggest (Marucco et al. [9]) that at $T>800^{\circ} \mathrm{C}$, the effective charge of interstitial cations is $\mathrm{Ti}^{4+}$, implying complete ionization of $\mathrm{Ti}^{3+}$ ions $\left(\mathrm{Ti}^{3+} \rightarrow \mathrm{Ti}^{4+}+\mathrm{e}^{-}, I_{3}=0.40 \mathrm{eV}\right)$ with consequent delocalization of the electrons. Even at very low temperatures it is not certain that the $\mathrm{Ti}^{3+}$ ions will be located in face-shared octahedral sites. This appears to be the case for $\mathrm{Ti}_{2} \mathrm{O}_{3}$, and we regard the shortest of the above linear defects as an element of $\mathrm{Ti}_{2} \mathrm{O}_{3}$ structure. However crystallographic studies of the phase transitions of $\mathrm{Ti}_{4} \mathrm{O}_{7}[14,15]$ show that in that phase $\mathrm{Ti}^{3+}-\mathrm{Ti}^{3+}$ pairing occurs between edge-shared octahedral sites, with only one of each face-shared octahedra containing a $\mathrm{Ti}^{3+}$ ion, for temperatures below $125 \mathrm{~K}$. At room temperature and above all $\mathrm{Ti}$ ions have effective charge 3.5 , indicating virtually complete delocalization of the electrons. Clearly the spatial extent of delocalization of electrons associated with small defects in $\mathrm{TiO}_{2-x}(x \lesssim 0.0035)$, and its temperature variation, remains an interesting problem, requiring further experimental and theoretical study.

4. Conclusion. - It is now necessary to seek further HREM evidence for the presence and interactions of cation interstitial defects described here. Computer simulations of HREM images (Bursill and Shen, in preparation) show that it should be possible to directly image, and positively identify, such small defects, and their aggregation, under very specific imaging conditions. In situ studies of the precipitation and dissolution of CSP, and complementary HREM studies, have already produced positive results and are in the course of publication [13].

In another paper the structure of oxygen vacancy defects in nonstoichiometric rutile is examined (Bursill and Blanchin, in preparation). It was again found possible to modify the classical model and derive a structure consistent with the common structural theme referred to above. Clearly 
the principles of point defect equilibria used for the analysis of a wide range of physical property measurements (electrical conductivity, thermogravimetry, ionic conductivities, internal friction, electron-spin-resonance, etc...) will need to be carefully reassessed in the light of such models.

Acknowledgments. - L. A. Bursill is grateful to University of Lyon for support of a visit to Lyon in 1982. The work was also supported by the University of Melbourne.

\section{References}

[1] Akse, J. R. and Whitehurst, H. B., J. Phys. Chem. Solids 39 (1978) 451.

[2] KofSTAD, P., Non stoichiometry, diffusion and electrical conductivity in binary metal oxides (WileyInterscience, New York) 1972, p. 22 and 137.

[3] Bursill, L. A. and Hyde, B. G., Prog. Solid State Chem. 7 (1972) 177.

[4] Baumard, J. F., Panis, D. and Anthony, A. M., J. Solid State Chem. 20 (1977) 43.

[5] Blanchin, M. G., Faisant, P., Picard, C., Ezzo, M. and Fontaine, G., Phys. Status Solidi (a)60 (1980) 357.

[6] Blanchin, M. G., Bursill, L. A., Hutchison, J. L. and GaI, P. L., J. Physique Colloq. 42 (1981) C3-95.

[7] Bursill, L. A., Blanchin, M. G. and Smith, D. J., Proc. R. Soc. Lond. A384 (1982) 135.

[8] Smith, D. J., Blanchin, M. G. and Bursill, L. A., Micron 13 (1982) 245.

[9] Marucco, J. F., Gautron, J. and Lemasson, P., J. Phys. Chem. Solids 42 (1981) 363.

[10] Gautron, J., Marucco, J. F. and Lemasson, P., Mater. Res. Bull. 16 (1981) 515.

[11] Hurlen, T., Acta Chem. Scand. 13 (1959) 365.

[12] Megaw, H. D., Crystal structures : a working approach (Saunders, New York) 1973, p. 39.

[13] Blanchin, M. G., Bursill, L. A. and Smith, D. J., Proc. Inter. Conf. defects in ionic crystals, Dublin (to be published in Radiation Effects), 1982.

[14] Marezio, M., McWhan, D. B., Dernier, P. D. and Remeika, J. P., J. Solid State Chem. 6 (1973) 213.

[15] Schlenker, C. and Marezio, M., Philos. Mag. B 42 (1980) 453. 